\title{
TECNOLOGIA DE INFORMACT̃̃O PARA APOIO AO ENSINO SUPERIOR: O USO DA FERRAMENTA MOODLE POR PROFESSORES DE CIÊNCIAS CONTÁBEIS
}

\section{HIGHER EDUCATION SUPPORTED BY INFORMATION TECHNOLOGY: THE USE OF MOODLE BY PROFESSORS IN ACCOUNTING COURSES}

\author{
Gilberto Perez ; ; Moisés Ari Zilber ; Ana Maria Roux Valentini Coelho Cesar ${ }^{\text {c; }}$ \\ Sergio Lex ${ }^{d}$; Alberto de Medeiros Jr. \\ Mestre e Doutor em Administração pela Universidade de São Paulo \\ Professor do Programa de Mestrado Profissional em Controladoria Empresarial da Universidade Presbiteriana Mackenzie; E-mail: gperez@mackenzie.br \\ ${ }^{b}$ Doutor em Administração pelo Programa de Pós-Graduação em Administração pela FEA/USP \\ Professor Doutor da área de Mestrado e Doutorado em Administração da Universidade Presbiteriana Mackenzie \\ E-mail:mazilber@mackenzie.com.br \\ Pós doutorado - Laboratory of Neuromodulation - Harvard Medical School \\ Pesquisadora, em regime de periodo integral, na Universidade Presbiteriana Mackenzie, \\ E-mail:rouxcesar@mackenzie.br \\ Doutor em Administração de Empresas pela Universidade Presbiteriana Mackenzie \\ Diretor do Centro de Ciências Sociais e Aplicadas da Universidade Presbiteriana Mackenzie; \\ E-mail:sslex@mackenzie.br \\ Doutor em Engenharia de Produção pela Escola Politécnica (USP) \\ Professor Adjunto e Pesquisador do Centro de Ciências Sociais e Aplicadas da Universidade Presbiteriana Mackenzie; \\ E-mail: alberto.medeiros@mackenzie.br
}

\section{Resumo}

Com esta pesquisa, buscou-se identificar e avaliar as principais características percebidas no uso da inovação tecnológica Moodle, levando-se em consideração os aspectos que podem contribuir para a sua adoção como ferramenta de apoio aos professores do ensino superior em Ciências Contábeis. A adoção foi estudada com base na Teoria de Difusão, que defende a existência de características ou atributos percebidos que afetam diretamente a adoção de inovações tecnológicas. A amostra da pesquisa foi composta de 31 professores de graduação do curso de Ciências Contábeis de uma Universidade ("Ômega") da cidade de São Paulo que conta com cerca de 35 mil alunos. Os dados coletados foram analisados com sistemas de equações estruturais, com a técnica PLS (Partial Least Square), por meio do software SMARTPLS ${ }^{\circledR}$. Os resultados obtidos indicam que as características: Experimentação, Facilidade de Uso e o Uso Voluntário da ferramenta foram percebidas pelos professores como determinantes na adoção do Moodle; sua percepção de melhoria se estende aos serviços prestados, aos processos de ensino-aprendizagem e à interação entre alunos e professores no acesso ao conhecimento e informações. Tais melhorias, na ótica dos professores, eram de difícil implantação antes da adoção do Moodle.

Palavras-chave: Tecnologia de Informação; Ensino em Contabilidade; Adoção de Inovação; Moodle.

\section{Abstract}

The aim of this research is to identify and assess the main features seen in the use of Moodle technological innovation, taking into account the aspects that may contribute to its adoption as a tool to support teachers in higher education in Accounting courses. The study on the adoption of Moodle was based on the Diffusion Theory, which asserts the existence of characteristics or attributes that directly affect the adoption of technological innovations. The study sample consisted of 31 professors of the undergraduate course in Accounting at the University ("Omega") of São Paulo, which has about 35,000 students. The collected data were analyzed by means of Structural Equation Modeling, the Partial Least Square (PLS) technique and smartPLS® software. The results indicate that Experimentation, Usability and Voluntary Use of the tool were regarded as determinants of the adoption of Moodle. Its noticeable improvement extends to services, to teaching-learning processes and to professor-student interaction when accessing knowledge and information. Such improvements, in the view of professors, were difficult to provide before the adoption of Moodle.

Keywords: Information Technology; Accounting Education; Adoption of Innovation; Moodle. 


\section{INTRODUÇÃO}

A constante busca pela melhoria de processos em paralelo à criação e oferta de novos produtos e serviços em diversos setores do mercado levou as organizações a investirem cifras cada vez maiores na aquisição de Sistemas de Informação - SI, que são conjuntos integrados de componentes (hardware, software, dados, redes e usuários) e Tecnologias de Informação - TI, que são o conjunto de formas de tecnologias utilizadas para a coleta, criação, armazenamento, processamento, comunicação, e distribuição de dados e informações, nos seus diversos tipos e formatos digitais (dados, sons e imagens) (PEREZ, 2006).

Assim como no mundo empresarial, as instituições de ensino vêm buscando soluções tecnológicas para melhorarem seu desempenho. As mudanças na forma tradicional de ensino começaram em meados do século 19 com o ensino por correspondência, caracterizando-se pelo recurso da palavra escrita ou impressa (LITTO, 2008). Em meados da década de 1970, as instituições de ensino passaram a usar os recursos de telecomunicação.

Na década de 1980 ocorreu a adoção dos recursos de fitas de áudio e vídeo e mais recentemente CDs e DVDs. Na década de 1990, o surgimento da Internet disponibilizada ao grande público marca a atual fase do ensino presencial ou à distância, possibilitando recursos interativos, ampliando-se a sua efetividade e o seu alcance graças à grande capilaridade da Web. Pode-se dizer que há, ainda, uma nova fase surgindo, que aproveitará os recursos dos chamados e-books combinados com vídeos e outros recursos para serem lidos (e assistidos) em leitores específicos, como o Kindle da Amazon ou nos diversos tablets disponíveis no mercado, com destaque para o iPad da Apple e os diversos modelos baseados no sistema operacional Android.

No ensino de contabilidade, há relatos de pesquisadores e educadores quanto ao sucesso do uso de Tecnologia de Informação no processo educacional (DAVID; MACCRACKEN; RECKERS, 2003). Para Dahawy e Kamel (2006), o uso da TI no ensino de contabilidade, possibilita: a) habilidade de corte de custos para atingir grande audiência; b) padronização da qualidade da instrução; c) Aprendizagem na qual o ritmo de cada aluno é respeitado e d) colaboração contínua entre os estudantes e os seus pares e os seus professores.

Visto que as instituições de ensino, assim como as organizações do mundo de negócios também estão investindo em sistemas e tecnologias de informação para melhorem seus resultados e desempenho dos seus professores e alunos, torna-se relevante entender como ocorre a adoção de uma ferramenta para apoio ao ensino em Contabilidade, no âmbito de uma instituição particular de ensino superior da cidade de São Paulo. Os participantes da pesquisa foram os professores desse curso, que utilizam este sistema em seu cotidiano.

O problema de pesquisa para o qual se buscou a resposta ficou assim enunciado: Quais são as características percebidas pelos professores usuários da inovação tecnológica Moodle, que podem contribuir para a sua adoção como ferramenta de apoio ao ensino de contabilidade?

O objetivo geral da pesquisa foi identificar e avaliar as principais características percebidas no uso da inovação tecnológica Moodle, levando em consideração os aspectos que podem contribuir para a sua adoção como ferramenta de apoio aos professores do ensino superior em Ciências Contábeis. Os objetivos específicos foram: 1) verificar como os professores usuários do Moodle perceberam esses fatores como influenciadores na adoção do sistema; 2) verificar alguns resultados obtidos por eles a partir da adoção e validar um modelo estrutural para avaliar a adoção do sistema Moodle.

Embora o Moodle, como boa parte dos sistemas de informação apresente várias funcionalidades (indicadas no capítulo dois - subitem quatro), que podem ser utilizadas em 
níveis distintos, a sua adoção/uso foi avaliada de forma geral, pela somatória das funções utilizadas pelos respondentes, e não por funções individuais, ou seja, a pesquisa se referiu sempre ao Moodle, não a uma, ou algumas de suas funções.

\section{REFERENCIAL TEÓRICO}

\subsection{Conceitos de Inovação}

O termo inovação tem como origem o latim - innovare - que significa fazer algo novo. Para os autores Tidd, Bessant e Pavitt (2005), a inovação deve ser entendida como um processo que visa transformar uma oportunidade em novas idéias e colocá-las amplamente em prática. Ainda de acordo com esses autores, a inovação é o ato ou efeito de inovar, isto é, tornar algo novo; renovar; ou introduzir uma novidade. O termo eventualmente causa confusão, pois as pessoas tendem a entender inovação como invenção.

Para Pennings (1998) pode-se entender a inovação como a adoção de uma idéia, a qual é tida como nova para o indivíduo ou outra entidade que a adota. Nesse sentido estão inclusos novos produtos ou serviços, novas tecnologias para produzir ou entregar o produto ou serviço, e novos procedimentos, sistemas e arranjos sociais. O processo de inovação também inclui busca e descoberta, experimentação, desenvolvimento, imitação e adoção de novos produtos, novos processos de produção e novas formas organizacionais.

Schumpeter (1982) alerta para o fato de que a inovação pode assumir várias formas não sendo necessário que se invente algo novo, por exemplo, pode-se submeter uma idéia já existente a uma nova forma de realizá-la ou a uma nova situação. $\mathrm{Na}$ ótica do usuário uma inovação é qualquer idéia ou produto percebido pelo consumidor potencial como sendo algo novo. Para Jelinek (1997) inovação é uma atividade coletiva que ocorre com o passar do tempo e com revisão continua dos alicerces cognitivos e compartilhados dos participantes. Para Drucker (2004) a inovação pode ser introduzida por meio de mudanças capazes de criar novas melhorias de desempenho organizacional. Basicamente, ela pode ocorrer de duas formas: a inovação na forma de mudanças em produtos e serviços e a inovação na forma como o produto ou serviço passam a ser produzidos ou oferecidos (TIDD; BESSANT; PAVITT, 2005).

Apesar de a inovação e a tecnologia caminharem lado a lado, a inovação não implica necessariamente na criação, produção e comercialização apenas dos maiores avanços daquilo que é tido como o estado da arte em tecnologia (inovação radical). Ela também pode incluir mudanças em pequena escala nas tecnologias já utilizadas atualmente, caracterizando uma melhoria, mudança gradativa ou inovação incremental (TIDD; BESSANT; PAVITT, 2005). Inovações no uso de sistemas de informações tipicamente implicam em mudanças de menor escala em geral associadas com o redesenho de processos e reformulações de métodos de trabalho.

\subsection{Difusão e Adoção da Inovação}

Segundo Rogers (1983), a teoria da difusão de inovação (TDI) começou a ser desenvolvida na década de 1930. O autor aponta na TDI, dentre outros aspectos, as características inerentes 
à própria inovação, bem como os elementos ligados aos fatores organizacionais internos, que podem aumentar a taxa de usuários adotantes de uma inovação tecnológica, ou não, ao longo do tempo. Esse aumento da taxa de adoção é o ponto central da TDI.

A difusão de uma inovação é o processo de sua comunicação em determinado contexto social envolvendo indivíduos e grupos, geralmente integrantes de uma organização. Por sua vez, a adoção de uma inovação também é um processo, no qual, os indivíduos e grupos decidem pelo seu uso, como melhor curso de ação disponível. O oposto da adoção é a rejeição, ou seja, quando ocorre a decisão pela não adoção. Rogers (2003) define a difusão de uma inovação como um tipo de comunicação social, no qual as mensagens estão relacionadas com novas idéias e são transmitidas ao longo do tempo, por meio de determinados canais, entre os vários membros de um sistema social.

Nas últimas décadas vários autores estudaram as principais características ou atributos percebidos em uma inovação que facilitam a sua adoção, inclusive as inovações em TI (ROGERS, 1983; MOORE; BENBASAT, 1991; KARAHANNA; STRAUB; CHERVANY, 1999; TENG; GROVER; GÜTTLER, 2002; AHUJA; THATCHER, 2005). A forma pela qual uma inovação é adotada depende diretamente dos atributos percebidos nessa inovação por seus usuários. A identificação de cinco atributos ou características percebidas da inovação é derivada da pesquisa de Rogers (1983) e da literatura sobre a difusão de inovação. Larsen e McGuire (1998) referem-se a tais atributos ou características como sendo atributos universais para estudos de adoção de inovações. Esses atributos são: Vantagem Relativa; Compatibilidade; Complexidade; Experimentação e Observabilidade.

Estas cinco características foram estudadas por Moore e Benbasat (1991), que desenvolveram um instrumento para avaliação das várias percepções que um indivíduo pode ter sobre as características de uso de uma inovação em SI/TI. Esses autores introduziram três novos atributos: imagem, uso voluntário e demonstração de resultado e adaptaram ao seu contexto de estudo os atributos originais de complexidade e observabilidade, que foram denominados, respectivamente, por facilidade de uso e visibilidade. As características ou atributos percebidos de uma inovação estudados pelos dois autores são detalhados no quadro 1. Essas características foram utilizadas no modelo de pesquisa conforme é detalhado na seção de metodologia.

\begin{tabular}{|c|c|c|}
\hline Característica & Descrição & Autor \\
\hline Vantagem Relativa & $\begin{array}{c}\text { Grau em que uma inovação é percebida como melhor que } \\
\text { seu precursor. }\end{array}$ & Rogers (1983) \\
\hline Compatibilidade & $\begin{array}{l}\text { Grau em que uma inovação é percebida como consistente } \\
\text { com valores, necessidade e experiências dos adotantes } \\
\text { potenciais. }\end{array}$ & Rogers (1983) \\
\hline Experimentação & $\begin{array}{l}\text { Grau em que uma inovação pode ser experimentada antes } \\
\text { da adoção. }\end{array}$ & Rogers (1983) \\
\hline Facilidade de Uso & Grau em que uma inovação é percebida como fácil de usar. & Moore e Benbasat (1991) \\
\hline Imagem & $\begin{array}{c}\text { Grau em que o uso de uma inovação é percebido para } \\
\text { melhorar a imagem de um indivíduo ou status de um } \\
\text { sistema social. }\end{array}$ & Moore e Benbasat (1991) \\
\hline Uso Voluntário & $\begin{array}{c}\text { Grau em que o uso de uma inovação é percebido como } \\
\text { voluntário ou espontâneo. }\end{array}$ & Moore e Benbasat (1991) \\
\hline Visibilidade & $\begin{array}{l}\text { Grau em que uma inovação se torna visível para os } \\
\text { indivíduos ou grupos de uma organização. }\end{array}$ & Moore e Benbasat (1991) \\
\hline $\begin{array}{l}\text { Demonstração de } \\
\text { Resultado }\end{array}$ & $\begin{array}{l}\text { Grau em que os resultados do uso de uma inovação são } \\
\text { tangíveis. }\end{array}$ & Moore e Benbasat (1991) \\
\hline
\end{tabular}

Quadro 1: Características percebidas no uso de uma inovação tecnológica

Fonte: adaptado de Rogers (1983) e Moore e Benbasat (1991) 
Rogers (2003) defende que as cinco características identificadas em seu estudo: vantagem relativa, compatibilidade, complexidade, experimentação e observabilidade podem explicar cerca de $49 \%$ a $85 \%$ da variância da taxa de adoção. Em tese, com a introdução das três novas características identificadas por Moore e Benbasat (1991), a taxa de adoção de uma inovação de SI/TI deveria ser mais bem avaliada. Como as características estudadas por esses últimos autores são aquelas percebidas pelo uso da inovação, esta pesquisa utilizará os termos adoção e/ou adoção/uso, com o mesmo significado.

\subsection{Conceitos de Sistemas e Tecnologias de Informação}

As informações originalmente eram colecionadas e depois comunicadas por relatórios manuscritos ou datilografados, ou, quando transformadas em conhecimento, apresentadas em aulas presenciais. Com o avanço da informatização nas empresas, elas passaram a ser processadas mais rapidamente e a serem apresentadas de forma mais segura e precisa, mais recentemente de forma online.

Os recursos tecnológicos: hardware, software, redes de telecomunicação e sistemas gerenciadores de dados são identificados como Tecnologia de Informação (TI). Estes, quando se destinam a atender os usuários, formam conjuntos conhecidos por Sistemas de Informação (SI), os quais resultam em relatórios administrativos (gráficos, áudio, formulários e documentos empresariais) identificados como produtos de informação, que auxiliam os profissionais nas decisões a serem tomadas (O'BRIEN; MARAKAS, 2008).

Para Laudon e Laudon (2011, p. 9) um sistema de informação é:

[...] um conjunto de componentes inter-relacionados que coleta (ou recupera), processa, armazena e distribui informações destinadas a apoiar a tomada de decisões, a coordenação e o controle de uma organização, [...] esses sistemas também auxiliam os gerentes e trabalhadores a analisar problemas, visualizar assuntos complexos e criar novos produtos.

Para Turban et al. (2010, p.59), "um SI coleta, processa, armazena, analisa e dissemina informações com um propósito específico". Os SI exercem três importantes papéis em todos os tipos de organização (O'BRIEN; MARAKAS, 2008): 1) Suportar as operações; 2) Suportar as estratégias competitivas; 3 ) Suportar as decisões.

O suporte às operações é obtido principalmente por sistemas transacionais. O suporte às estratégias competitivas pode-se dar pelos usos inovadores de sistemas de informação, dentre os quais se destacam as diversas modalidades de comércio eletrônico, tanto em sua relação com o consumidor final, quanto com outra empresa. O suporte à decisão, finalmente, é feito por sistemas de informação gerencial ou executiva, por recursos de armazenamento e mineração de dados (Data Warehouse / Data Mining), ou pelos sistemas de suporte à decisão.

O uso de um recurso online para Ensino a Distância pode ser visto, por isso, como um suporte às estratégias competitivas, uma vez que além de inovador, ele possibilita às instituições de ensino ampliar o seu raio de ação atingindo os públicos mais longínquos.

\subsection{Sistemas de Informação como recurso complementar de ensino}

Até há pouco tempo, as aulas presenciais utilizavam poucos recursos de Sistemas de Informação. Excluídas as aulas práticas que exigem aparelhos especiais ou aulas que exigem softwares específicos e, portanto, computadores em laboratórios de informática, as aulas eram 
ministradas com o auxílio do quadro negro e giz e quanto muito com o eventual apoio de retroprojetores e eventuais projetores de slides ou videocassete.

Mais recentemente passou-se a utilizar o chamado datashow, que se trata de um projetor de emissões digitais, ligado a um computador que pode reproduzir apresentações compostas por um sistema destinado a isso, dentre os quais se destaca o Powerpoint da Microsoft ${ }^{\circledR}$. Isso facilitou o uso de recursos complementares para ensino, uma vez que o mesmo computador pode transmitir vídeos a partir de CDs (Compact Disc) e DVDs (Digital Video Disc). Com o advento da Internet, surgem plataformas criadas originariamente para o ensino à distância que também são utilizados como recurso complementar ao ensino presencial.

Essa plataforma utilizada na Web é conhecida por SGA - Sistema de Gestão da Aprendizagem - (em inglês, LMS - Learning Management System) e trata-se de uma categoria de sistema de informação. Algumas instituições com cursos predominantemente presenciais optam em utilizar o SGA como recurso para aulas de reforço para os alunos que foram reprovados em uma disciplina e dependem de sua aprovação para continuação ou finalização do curso, ou então a utilizam como um recurso complementar à aula presencial, principalmente como repositório de material para aprendizagem e controle de tarefas, sendo este o caso da Universidade "Ômega".

O SGA passou a ser, portanto, um importante elemento como recurso de ensino. Existem diversas plataformas, dentre as quais se destaca uma que tem boa aceitação por sua facilidade de manuseio e por ser um software com fonte aberta e livre baseado na Internet. Trata-se do Moodle, (Modular Object-Oriented Dynamic Learning Environment - Ambiente Modular de Ensino Dinâmico Orientado ao Objeto) que é um sistema de apoio à aprendizagem, executado em ambiente virtual.

Ele vem sendo desenvolvido de forma colaborativa do qual participam voluntariamente administradores de sistema, professores, pesquisadores, designers instrucionais, desenvolvedores, programadores e usuários de todo o mundo, apoiando-se no modelo pedagógico do construtivismo social e na militância por programas gratuitos de código aberto.

O seu conceito começou a ser desenvolvido a partir de 2001, pelo australiano Martin Dougiamas, educador e cientista em computação, como base de sua tese The use of Open Source software to support a social constructionist epistemology of teaching and learning within Internet-based communities of reflective inquiry no Science and Mathematics Education Centre da Universidade de Tecnologia localizada em Perth (Austrália).

Esse SGA é composto por um sistema de administração de atividades educacionais voltado à aprendizagem colaborativa, o que possibilita a integração entre estudantes e docentes em cursos online (COLE; FOSTER, 2008). As estatísticas apresentam novos números diariamente, mas eles sempre são muito relevantes.

Em dezembro de 2012 o Moodle era adotado em cerca de 220 países, em 80 línguas diferentes, com aproximadamente 72 mil sites e 6,9 milhões de cursos registrados, atingindo cerca de 64 milhões usuários e 1,3 milhões de professores. (http://moodle.org/stats/).

O Moodle pode ser utilizado em três diferentes formatos (COLE; FOSTER, 2008):

1. social: com temas discutidos em um fórum publicado na página principal;

2. semanal: o curso é organizado em semanas, com datas de início e término;

3. tópicos: cada assunto estudado ou discutido representa um tópico. Não possui limite de tempo pré-definido.

Ele apresenta recursos e atividades que podem ser utilizados tanto para cursos à distância, 
como para complementar o ensino presencial. Os seus principais recursos são apresentados no quadro 2:

\begin{tabular}{|c|l|}
\hline Recurso & \multicolumn{1}{c|}{ Finalidade } \\
\hline Livro & $\begin{array}{l}\text { Material de estudo em páginas independentes para cada capítulo. A escolha da página é feita } \\
\text { por um clique no título do capítulo em uma coluna de sumário. }\end{array}$ \\
\hline $\begin{array}{c}\text { Página de } \\
\text { texto simples }\end{array}$ & $\begin{array}{l}\text { Página que contém textos simples. Apesar de não serem muito atrativas, elas são uma forma } \\
\text { rápida de expor algumas informações ou instruções. }\end{array}$ \\
\hline $\begin{array}{c}\text { Página Web } \\
\text { Recurso que facilita o desenvolvimento de uma página web completa. O código é }\end{array}$ \\
\hline $\begin{array}{c}\text { arma arquivo } \\
\text { ou site }\end{array}$ & $\begin{array}{l}\text { Um dos recursos mais utilizados pelos professores. Permite o acesso para download a um } \\
\text { arquivo armazenado em um diretório ou a um link a qualquer página HTML de quaisquer } \\
\text { sites ou a um arquivo disponível em outro site (como arquivos PDF, p.ex.). }\end{array}$ \\
\hline $\begin{array}{c}\text { Visualização } \\
\text { de diretório }\end{array}$ & $\begin{array}{l}\text { Permite o acesso a um diretório selecionado (e seus subdiretórios) da sua área de arquivos } \\
\text { do curso possibilitando aos estudantes navegar e visualizar todos os arquivos nele contidos. }\end{array}$ \\
\hline $\begin{array}{c}\text { Inserção de } \\
\text { rótulo }\end{array}$ & $\begin{array}{l}\text { Possibilita inserir textos e imagens na página principal do curso, sendo, visíveis tão logo o } \\
\text { estudante acessa a sua sala de aulas virtual. }\end{array}$ \\
\hline
\end{tabular}

\section{Quadro 2: Principais recursos do Moodle}

Fonte: Adaptado de Cole e Foster (2008) e menu de ajuda do Moodle (quadro 3).

Além dos recursos o Moodle oferece, ainda, diversas atividades para uso remoto

\begin{tabular}{|c|c|}
\hline Atividade & Finalidade \\
\hline Base de dados & $\begin{array}{l}\text { Permite criar, mostrar e buscar um banco de dados sobre qualquer tópico com formato e } \\
\text { estrutura dos itens quase ilimitados, incluindo imagens, arquivos, URLs, números e texto. }\end{array}$ \\
\hline Chat & $\begin{array}{l}\text { Permite uma discussão textual via web em modalidade síncrona. Essa é uma maneira veloz } \\
\text { de obter diversos pontos de vista sobre um assunto, onde todos podem publicar textos ao } \\
\text { mesmo tempo. }\end{array}$ \\
\hline Escolha & $\begin{array}{l}\text { Módulo muito simples que se configura de uma única pergunta com diversas opções de } \\
\text { resposta. Serve para pesquisas rápidas de opinião, para estimular a reflexão sobre um } \\
\text { tópico, para escolher entre sugestões dadas para a solução de um problema ou para obter a } \\
\text { permissão de utilizar dados pessoais dos estudantes em pesquisas do professor. }\end{array}$ \\
\hline Fórum & $\begin{array}{l}\text { Atividade muito importante. Tem diversos tipos de estrutura e podem incluir a avaliação } \\
\text { recíproca de cada mensagem. As mensagens são visualizadas em diversos formatos e podem } \\
\text { incluir anexos. }\end{array}$ \\
\hline Glossário & $\begin{array}{l}\text { Permite que os participantes criem e atualizem uma lista de definições como em um } \\
\text { dicionário ou em um FAQ (Frequently Asked Questions). s listas podem ser visualizadas em } \\
\text { diversos formatos. }\end{array}$ \\
\hline $\begin{array}{l}\text { Laboratório de } \\
\text { avaliação }\end{array}$ & $\begin{array}{l}\text { Atividade de avaliação entre os participantes com uma vasta gama de opções. Eles podem } \\
\text { avaliar os projetos de outros participantes e exemplos de projeto em diversos modos. Este } \\
\text { módulo também organiza o recebimento e a distribuição destas avaliações. }\end{array}$ \\
\hline Lição & $\begin{array}{l}\text { É uma das mais complexas atividades do Moodle onde se publica o conteúdo em um modo } \\
\text { interessante e flexível. Ela consiste em certo número de páginas. Cada página, normalmente, } \\
\text { termina com uma questão e uma série de possíveis respostas. Dependendo da resposta } \\
\text { escolhida pelo aluno, ou ele passa para a próxima página ou é levado de volta para uma } \\
\text { página anterior ou a outra página de reforço. }\end{array}$ \\
\hline
\end{tabular}


o Uso da Ferramenta Moodle por Professores de Ciências Contábeis

Continuação Quadro 3

\begin{tabular}{|c|l|}
\hline Atividade & \multicolumn{1}{c|}{ Finalidade } \\
\hline Blog & $\begin{array}{l}\text { Permite criar e manter blog simples, cuja estrutura permite a atualização rápida a partir de } \\
\text { acréscimos dos artigos (posts). }\end{array}$ \\
\hline Pesquisa & $\begin{array}{l}\text { Permite construir pesquisas do tipo survey a partir de formulários usando uma grande } \\
\text { variedade de formatos de perguntas para reunir dados de usuários. }\end{array}$ \\
\hline Questionário & $\begin{array}{l}\text { É uma das mais úteis atividades do Moodle. Trata-se de um instrumento de composição de } \\
\text { questões e de configuração de questionários em diversos tipos de questões: múltipla escolha, } \\
\text { verdadeiro ou falso, resposta breve, etc. }\end{array}$ \\
\hline Tarefas & $\begin{array}{l}\text { É a descrição ou enunciado de uma atividade a ser desenvolvida pelo participante, que pode } \\
\text { ser enviada em formato digital ao servidor do curso, p.ex., redações, projetos, relatórios, } \\
\text { imagens, etc. Ele inclui a possibilidade de descrever tarefas a serem realizadas offline (na } \\
\text { sala de aula, p.ex.) e de publicar o resultado da avaliação. Possui as seguintes modalidades: } \\
\text { avançada de carregamento de arquivos, texto online, envio de arquivo único, atividade offline. }\end{array}$ \\
\hline Wiki & $\begin{array}{l}\text { O que faz um wiki diferente das outras páginas da Internet é o fato de poder ser editado pelos } \\
\text { usuários que por ele navegam. O software colaborativo utilizado permite a edição coletiva dos } \\
\text { documentos usando um sistema que não necessita que o conteúdo tenha que ser revisto antes } \\
\text { da sua publicação. }\end{array}$ \\
\hline
\end{tabular}

Quadro 3: Principais atividades do Moodle

Fonte: Adaptado de Cole e Foster (2008) e menu de ajuda do Moodle

\subsection{Resultados do uso de Sistemas e Tecnologias de Informação}

Vários autores, ao longo do tempo, identificaram inúmeros resultados e melhorias internas obtidos com a introdução dos Sistemas e Tecnologias de Informação no mundo de negócios, em diversos segmentos distintos de atuação. Esses resultados vão desde o aprimoramento de processos, produtos e serviços existentes, até a criação de novos produtos que chegam ao mercado. O quadro 4 apresenta uma síntese desses resultados.

\begin{tabular}{|c|c|c|}
\hline Inovação & Descrição & Autor (es) \\
\hline $\begin{array}{l}\text { Criação de Novos Produtos/ } \\
\text { Serviços ou Processos }\end{array}$ & $\begin{array}{l}\text { Inovar constantemente com novos produtos, } \\
\text { processos e serviços competitivos }\end{array}$ & $\begin{array}{l}\text { Turban et al. (2006) } \\
\text { Pennings (1998) }\end{array}$ \\
\hline $\begin{array}{l}\text { Produtos/Serviços/Processos } \\
\text { Incrementados (melhorados) }\end{array}$ & $\begin{array}{l}\text { Produtos/serviços/processos existentes com } \\
\text { novas extensões competitivas }\end{array}$ & $\begin{array}{l}\text { Graeml (2003) } \\
\text { Ahuja e Thatcher (2005) } \\
\text { Turban et al. (2006) }\end{array}$ \\
\hline $\begin{array}{l}\text { Produtos/Serviços/Processos } \\
\text { Diferenciados }\end{array}$ & $\begin{array}{l}\text { Produtos/serviços/processos únicos para } \\
\text { ganho de vantagem ou valor adicionado }\end{array}$ & Turban et al. (2010) \\
\hline Processos Administrativos & $\begin{array}{l}\text { Sistemas que envolvem o componente } \\
\text { administrativo e impacta o sistema social de } \\
\text { uma organização }\end{array}$ & Pennings (1998) \\
\hline $\begin{array}{l}\text { Sistemas Intra/Inter- } \\
\text { organizacionais }\end{array}$ & $\begin{array}{l}\text { Conexão entre os sistemas de informação } \\
\text { das áreas de uma organização ou entre duas } \\
\text { organizações }\end{array}$ & Turban et al. (2006) \\
\hline $\begin{array}{l}\text { Alternativas nas Formas de } \\
\text { Ensino }\end{array}$ & $\begin{array}{l}\text { Sistemas que apresentem novas opções para } \\
\text { a melhoria do ensino }\end{array}$ & $\begin{array}{l}\text { Cavalcante e Vasconcellos } \\
(2006) \\
\text { Rodrigues et al. (2006) }\end{array}$ \\
\hline
\end{tabular}

Quadro 4: Resultados obtidos pelo uso de SI/TI

Fonte: Elaborado pelos autores, a partir da literatura pesquisada 


\section{UNIVERSIDADE "ÔMEGA" - A INSTITUIÇÃO DE ENSINO PESQUISADA}

Por questões de sigilo garantido, a universidade estudada foi denominada nesta pesquisa como Universidade "Ômega", que está situada no estado de São Paulo. Trata-se de uma instituição particular tradicional de ensino superior. O curso de Ciências Contábeis faz parte da unidade universitária de Administração e Ciências Econômicas e foi criado no início da década de 1960, sendo, um dos cursos com maior procura na Universidade. A Universidade oferece também, nessa unidade, cursos de Pós-Graduação Lato e Stricto Sensu tanto para o Mestrado, como Doutorado.

O sistema Moodle foi implantado em meados dos anos 2000, porém, seu uso foi institucionalizado nos últimos cinco anos (2008-2012), embora isto não signifique que os professores sejam obrigados a adotá-lo em sua prática de ensino. Apesar da não imposição, os professores das diversas unidades universitárias vêm adotando suas várias funcionalidades como apoio ao ensino presencial e, em alguns casos, também para o ensino a distância.

$\mathrm{Na}$ Universidade "Ômega" os diversos cursos de lato sensu utilizam intensivamente o recurso de link a arquivo ou site de Moodle e a atividade de tarefas na disciplina semipresencial de metodologia do trabalho científico. Os professores de graduação o utilizam principalmente para oferecer material complementar pelo recurso de link a arquivo e vem crescendo o uso das atividades de tarefa e questionário.

\section{PROCEDIMENTOS METODOLÓGICOS}

Com base nas proposições do problema de pesquisa e nos seus objetivos, criou-se um modelo estrutural de pesquisa, que pode ser observado na figura 1. Do processo de difusão/ adoção de uma inovação tecnológica proposto por (ROGERS, 2003) e do estudo de Moore e Benbasat (1991), identificaram-se as principais características percebidas pelos usuários de inovações tecnológicas afetam a sua de adoção. Essas características formaram a base para o desenvolvimento do questionário eletrônico utilizado para a coleta de dados junto aos professores da Universidade Ômega.

Não foram feitos estudos para validação das questões resultantes da junção das duas propostas teóricas (ROGERS, 1983; MOORE; BENBASAT, 1991) porque a natureza do estudo é descritiva e não se pretendeu obter uma escala para medir o nível de uso/adoção de inovação, de modo que se possam comparar diferentes instituições. $\mathrm{O}$ estudo foi feito em uma instituição e as respostas relacionadas às características percebidas no uso/adoção medem a percepção dos sujeitos acerca dessas características quando relacionadas às funções disponíveis no Moodle.

As assertivas do instrumento utilizado por Moore e Benbasat (1991) foram adaptadas e a elas, adicionaram-se outras, para se atingir os objetivos da pesquisa e, a qualificação dos respondentes. Ressalta-se, que um pré-teste foi realizado com sete respondentes, objetivandose a sua validação, após o que, o questionário foi enviado a todos potenciais respondentes (professores de Administração, Economia e Contabilidade). Para esta pesquisa e seus propósitos, apenas os professores do curso de Ciências Contábeis, que responderam o questionário, foram selecionados.

Na Figura 1 apresenta-se o modelo estrutural de pesquisa, composto por três níveis, sendo que no primeiro nível têm-se as variáveis relacionadas às características percebidas no uso de inovações; no segundo nível tem-se a variável adoção/uso da inovação e, no terceiro 
nível a variável relacionada aos resultados da adoção/uso do Moodle. Observe-se que a variável adoção/uso é variável dependente e, ao mesmo tempo, independente. Esse tipo de relacionamento mostra a natureza de interdependência do modelo proposto, sendo adequado o uso da Modelagem de Equações Estruturais para esse tipo de modelo (HAIR JR. et al., 1998).

Figura 1: Modelo Estrutural de Pesquisa

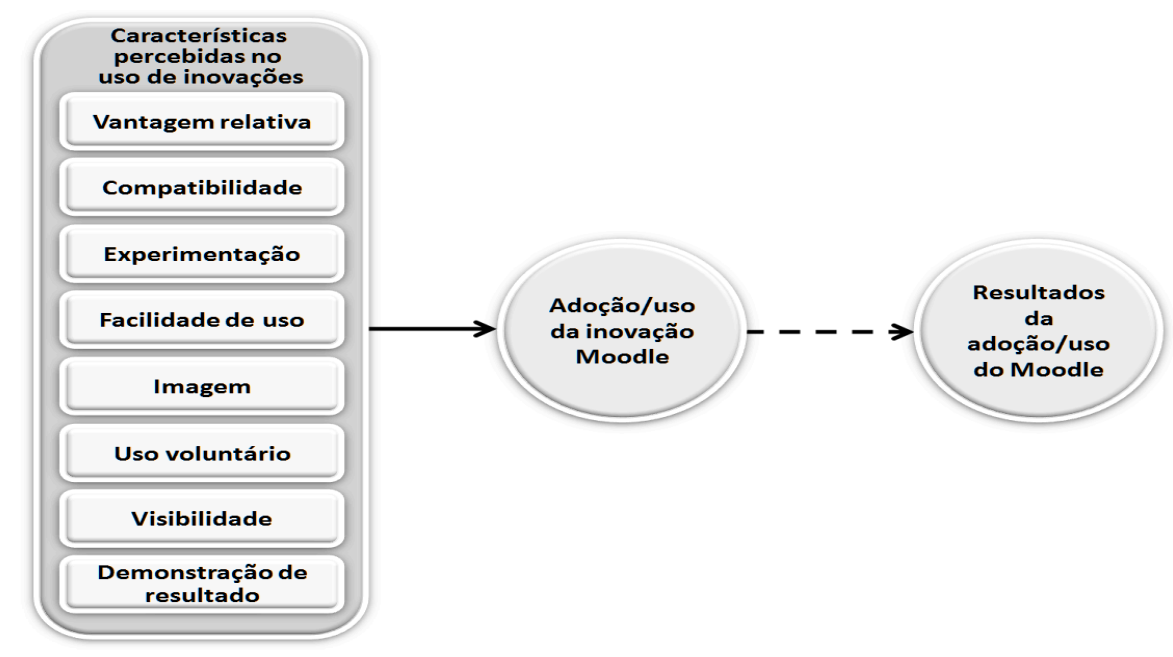

Fonte: Elaborado pelos autores

Para a identificação das variáveis preditoras, a cada etapa do modelo deve-se observar a direção das setas que ligam os construtos (variáveis latentes). Como esses são conceitos teóricos, são complexos e abstratos; cada um dos construtos do modelo é estimado por um conjunto de indicadores, sendo que a sua representação visual no modelo estrutural se dá por meio de setas que saem dos construtos (modelo reflexivo) (HAIR JR. et al., 1998).Pode-se observar a partir do quadro 4, que os resultados obtidos pelo uso de um SI podem ser alcançados pela criação e oferta de novos produtos/serviços e processos, bem como, pela melhoria daqueles já existentes, além das possibilidades de novos processos administrativos e novos processos entre e intraorganizacionais.

Uma questão importante a se destacar é que os resultados são avaliados pela percepção do respondente acerca dos mesmos. Essa percepção pode variar de sujeito para sujeito e esse tipo de avaliação, embora subjetivo, é usual em estudos comportamentais. Todavia, isto não representa um viés para esta pesquisa vez que o problema de pesquisa propõe a avaliação da percepção dos usuários, e não a identificação de resultados objetivos, como número de acessos, indicadores de desempenho acadêmico, indicadores de avaliação de desempenho de professores, dentre outros possíveis.

Para a validação do esquema de pesquisa proposto na figura 1 definiu-se como variável Dependente (VD): A adoção de uma inovação tecnológica (Moodle). As variáveis independentes (VI) foram representadas pelo conjunto de 8 variáveis indicadas no quadro 1 . Quando as variáveis estudadas estão relacionadas a conceitos complexos (Adoção/Uso de uma inovação tecnológica / Os resultados do uso de uma inovação tecnológica), o uso de construtos, ou variáveis latentes formativas/reflexivas (caminhos que recebem/emitem seta no modelo estrutural) podem facilitar o entendimento desses conceitos.

De acordo com Hair Jr. et al. (2005), os construtos podem ser entendidos como conceitos teóricos a serem utilizados pelos pesquisadores, os quais podem ser definidos em termos abstratos, mas que não podem ser medidos de forma direta. No modelo quantitativo proposto, a Variável Dependente ficou definida pela Adoção/Uso da Inovação Tecnológica Moodle, que é diretamente afetada pelo conjunto de características/atributos percebidos no uso de uma 
inovação tecnológica em SI/TI (quadro 1).

Os resultados obtidos pelo uso da inovação em SI foram identificados pelas variáveis do quadro 4. Pode-se observar a partir desse quadro, que os resultados obtidos pelo uso de um SI podem ser alcançados pela criação e oferta de novos produtos/serviços e processos, bem como a melhoria daqueles já existentes, além das possibilidades de novos processos administrativos e novos processos entre e intraorganizacionais.

Para a amostra utilizada nesta pesquisa, os elementos-chave dos quais se buscou obter informações foram os professores usuários do Moodle que responderam o questionário que utiliza escalas quantitativas. A amostra utilizada foi do tipo não probabilística por conveniência, devido às dificuldades e limitações físicas para se garantir a aplicação de uma técnica de amostragem probabilística. Para o tamanho da amostra as recomendações de Hair Jr. et al. (2005) são para uma amostra preferencialmente superior a 100 respondentes, ou deve-se ter o número de respondentes de, no mínimo, cinco vezes o número de variáveis latentes em estudo $(5 \times 10=50)$. A amostra obtida para os 31 professores respondentes da pesquisa ficou abaixo dessa recomendação, porém, quando submetida à Modelagem de Equação Estrutural com a técnica PLS, os resultados obtidos mostraram-se consistentes.

Levando-se em conta os 31 questionários da amostra e, obedecendo ao critério de significância $(<0,05)$, constatou-se com software $G^{*}$ Power ${ }^{\circledR}$ versão 3.1 , que os coeficientes $\mathrm{R}^{2}$ obtidos no modelo estrutural para os construtos adoção/uso e resultados da adoção/uso deveriam ser maiores ou iguais a 0,4 e 0,3 , respectivamente, o que de fato ocorreu, conforme apresentado nos resultados da pesquisa. Esses resultados estão em consonância com as recomendações de Faul et al. (2009) e corroboraram com a utilização da técnica PLS para a amostra utilizada.

\subsection{Técnicas para a análise dos Dados}

Dentre as técnicas de análise multivariadas adotou-se neste estudo a técnica de análise multivariada denominada: Modelagem de Equação Estrutural. Nesse caso, utilizou-se o software SmartPLS ${ }^{\circledR}$ Versão: 2.0.M3, executando em ambiente Windows XP ${ }^{\circledR}$. O termo Modelagem de Equação Estrutural (Structural Equation Modeling - SEM) não designa uma técnica única, mas, sim, uma família de procedimentos relacionados (KLINE, 2005). Para esse autor, outros termos como a análise da estrutura de covariância e a modelagem da estrutura de covariância também são utilizadas na literatura para classificar essas várias técnicas juntas em uma única técnica. Tenenhaus et al. (2004) enfatizam que o uso do PLS em Modelagem de Equações Estruturais é adequado, em casos de amostras pequenas e, sem a necessidade normatização das variáveis.

Segundo Byrne (2001), ao se trabalhar com SEM, é recomendável que se faça a distinção entre variáveis latentes exógenas e as variáveis latentes endógenas. A variável exógena atua como preditora ou "causa" para outros construtos ou variáveis no modelo (HAIR et. al., 2005). As variáveis latentes exógenas são sinônimo de variáveis independentes, uma vez que provocam flutuações no valor de outras variáveis latentes no modelo. Mudanças no valor das variáveis exógenas não são explicadas pelo modelo. São influenciadas por fatores externos ao modelo (BYRNE, 2001). Já a variável latente endógena é a que atua como dependente ou "de resultado" em pelo menos uma relação causal (HAIR Jr. et. al., 2005). O termo variável latente endógena é sinônimo de variável dependente, sendo essa variável afetada por uma variável exógena no modelo, direta ou indiretamente (BYRNE, 2001). 


\subsection{Hipóteses e Pressupostos da Pesquisa}

Segundo Marconi e Lakatos (2007), depois de se formular o problema de pesquisa e após definir os seus objetivos gerais e específicos, a próxima etapa é a proposição de uma possível resposta, a qual se assume como sendo "suposta, provável e provisória" ao problema, isto é, uma hipótese. A hipótese indica uma possível solução para o problema que está sendo pesquisado, e constitui uma interpretação provisória ou antecipada, que a pesquisa pretende confirmar (PÁDUA, 1996). Com base no modelo estrutural e no problema de pesquisa proposto, foram pesquisadas as possibilidades de rejeição ou não das seguintes hipóteses nas quais são apresentadas diversas características, bem como processos e serviços, e sua relação com a adoção do Moodle.

H1: A Vantagem Relativa afeta significativamente a adoção do Moodle.

H2: O Uso Voluntário afeta significativamente a adoção do Moodle.

H3: A Compatibilidade afeta significativamente a adoção do Moodle.

H4: A Imagem afeta significativamente a adoção do Moodle.

H5: A Facilidade de Uso afeta significativamente a adoção do Moodle.

H6: A Demonstração de Resultado afeta significativamente a adoção do Moodle.

H7: A Visibilidade afeta significativamente a adoção do Moodle.

H8: A Experimentação afeta significativamente a adoção do Moodle.

H9: A Adoção do Moodle afeta positivamente os processos e serviços (Resultados do Uso) realizados pelos professores.

\subsection{Instrumento de Coleta de Dados}

O instrumento de coleta de dados adotado foi o questionário, com perguntas predominantemente fechadas. Adotou-se uma escala numérica de $\mathbf{5}$ pontos, para avaliação das perguntas assertivas fechadas. A escala tinha a seguinte direção: a atribuição das notas: 1 ao valor mínimo e 5 ao valor máximo, às assertivas constantes no quadro 5.

Quadro 5: Variáveis utilizadas no modelo estrutura

\begin{tabular}{|l|c|}
\hline Construto/Assertiva & Variável \\
\hline Uso do Moodle & Us1 \\
\hline Considero-me um usuário intensivo do Moodle & Us2 \\
\hline Assim que possível pretendo utilizar mais funcionalidades do Moodle & Us3 \\
\hline De uma forma geral, considero que utilizo o MOODLE de forma satisfatória & CPI9 \\
\hline Compatibilidade & CPI21 \\
\hline Entendo que o uso do Moodle ajusta-se bem à forma que eu gosto de trabalhar & CPI23 \\
\hline O uso do Moodle ajusta-se ao meu estilo de trabalho & CPI7 \\
\hline O uso do Moodle é compatível com todos os aspectos do meu trabalho & CPI15 \\
\hline Demonstração de Resultado & CPI17 \\
\hline Acredito que posso comunicar aos outros as conseqüências do uso do Moodle & \\
\hline Os resultados do uso do Moodle são aparentes para mim & \\
\hline Não tenho dificuldades para explicar por que o uso do Moodle pode ou não ser benéfico & \\
\hline
\end{tabular}




\begin{tabular}{|c|c|}
\hline Construto/Assertiva & Variável \\
\hline Não tive dificuldades para dizer aos outros sobre os resultados do uso do Moodle & CPI26 \\
\hline \multicolumn{2}{|l|}{ Experimentação } \\
\hline Eu tive várias oportunidades de experimentar aplicações para o Moodle & CPI3 \\
\hline Antes de decidir a usar o Moodle eu pude experimentá-lo corretamente & CPI12 \\
\hline Foi-me permitido usar o Moodle a título de teste, o tempo suficiente para entender o que poderia fazer & CPI24 \\
\hline \multicolumn{2}{|l|}{ Facilidade de Uso } \\
\hline Acredito que é fácil utilizar o Moodle para fazer o que eu preciso fazer & CPI6 \\
\hline Minha interação como o Moodle é clara e de fácil compreensão & CPI14 \\
\hline No geral, acredito que o Moodle é fácil de ser utilizado & CPI20 \\
\hline Aprender a usar o Moodle foi fácil para mim & CPI22 \\
\hline \multicolumn{2}{|l|}{ Imagem } \\
\hline As pessoas da minha instituição que usam o Moodle têm um perfil diferenciado & CPI4 \\
\hline As pessoas da minha instituição que usam o Moodle têm maior prestígio do que aquelas que não usam & CPI11 \\
\hline Usar o Moodle é um símbolo de status em minha instituição & CPI27 \\
\hline \multicolumn{2}{|l|}{ Vantagem Relativa } \\
\hline Usando o Moodle posso realizar minhas tarefas mais rapidamente & CPI2 \\
\hline O uso do Moodle torna mais fácil a realização do meu trabalho & CPI5 \\
\hline O uso do Moodle me possibilita um maior controle do meu trabalho & CPI 8 \\
\hline O uso do Moodle melhora a qualidade do meu trabalho & CPI 13 \\
\hline O uso do Moodle melhora minha efetividade no trabalho & CPI 25 \\
\hline \multicolumn{2}{|l|}{ Visibilidade } \\
\hline O uso do Moodle não é percebido em minha instituição & CPI 10 \\
\hline É fácil observar outras pessoas utilizando o Moodle em minha instituição & CPI 16 \\
\hline Na minha instituição pode-se encontrar o Moodle em vários computadores & CPI 19 \\
\hline \multicolumn{2}{|l|}{ Uso Voluntário } \\
\hline Meus superiores não me obrigam a utilizar o Moodle & CPI1 \\
\hline Embora seja útil, usar o Moodle não é obrigatório em meu trabalho & CPI18 \\
\hline \multicolumn{2}{|l|}{ Resultado do Uso } \\
\hline O uso do MOODLE me possibilita a criação de novos serviços ou processos & RU1 \\
\hline O uso do MOODLE me permite melhorar a forma de realizar serviços ou processos atuais & RU2 \\
\hline O uso do MOODLE me permite a criação de serviços ou processos diferenciados & RU3 \\
\hline O uso do MOODLE me possibilita inovar a forma de administrar a execução de minhas atividades & RU4 \\
\hline O uso do MOODLE me permite o acesso a novos conhecimentos & RU5 \\
\hline O uso do MOODLE me propicia novas alternativas para o método de ensino & RU6 \\
\hline Minhas dúvidas com relação ao uso do MOODLE são sanadas de forma satisfatória pelo suporte & RU7 \\
\hline O uso do MOODLE facilita o acesso às informações & RU8 \\
\hline O uso do MOODLE me permite criar soluções para os alunos, antes impensadas & RU9 \\
\hline Outras inovações/tecnologias foram introduzidas a partir da implantação do MOODLE & RU10 \\
\hline A Minha instituição oferece um bom suporte ao uso do MOODLE & RU11 \\
\hline
\end{tabular}

Fonte: Elaborado pelos autores.

\section{APRESENTAÇÃO E ANÁLISE DOS RESULTADOS}

Obteve-se ao todo, um total de 31 professores participantes da pesquisa, sendo que todos lecionam no curso de Ciências Contábeis. Destes, 10 possuem a titulação de doutorado e os demais são mestres. Inicialmente procedeu-se o processamento do modelo estrutural proposto, para a sua validação e obtenção dos coeficientes de regressão. Os dados foram coletados no 
segundo semestre de 2010.

\subsection{Avaliação do Modelo de Mensuração}

Os resultados do processamento do modelo estrutural inicialmente proposto mostraramse adequados, de tal forma que, a maioria das variáveis observadas (Us1, CPI1, CPI2, RU1, RU2,... etc.) foram mantidas no modelo, pois apresentaram coeficientes de correlação superiores ou próximos de 0,7. Foram retiradas as variáveis Us2, CPI10, CPI22, CPI24 e RU6 das suas respectivas variáveis latentes, pois apresentaram coeficientes de correlação com valores em torno de 0,5 . O modelo ajustado foi então processado novamente cujo resultado está indicado na figura 2, onde, a adoção/uso do Moodle está indicada pela variável Adoc-Uso. As variáveis Us1 e Us2 foram utilizadas como indicadores do construto Adoc-Uso e foram indicadas na figura 2 a título de esclarecimento.

Figura 2: Modelo de mensuração (modelo estrutural ajustado)

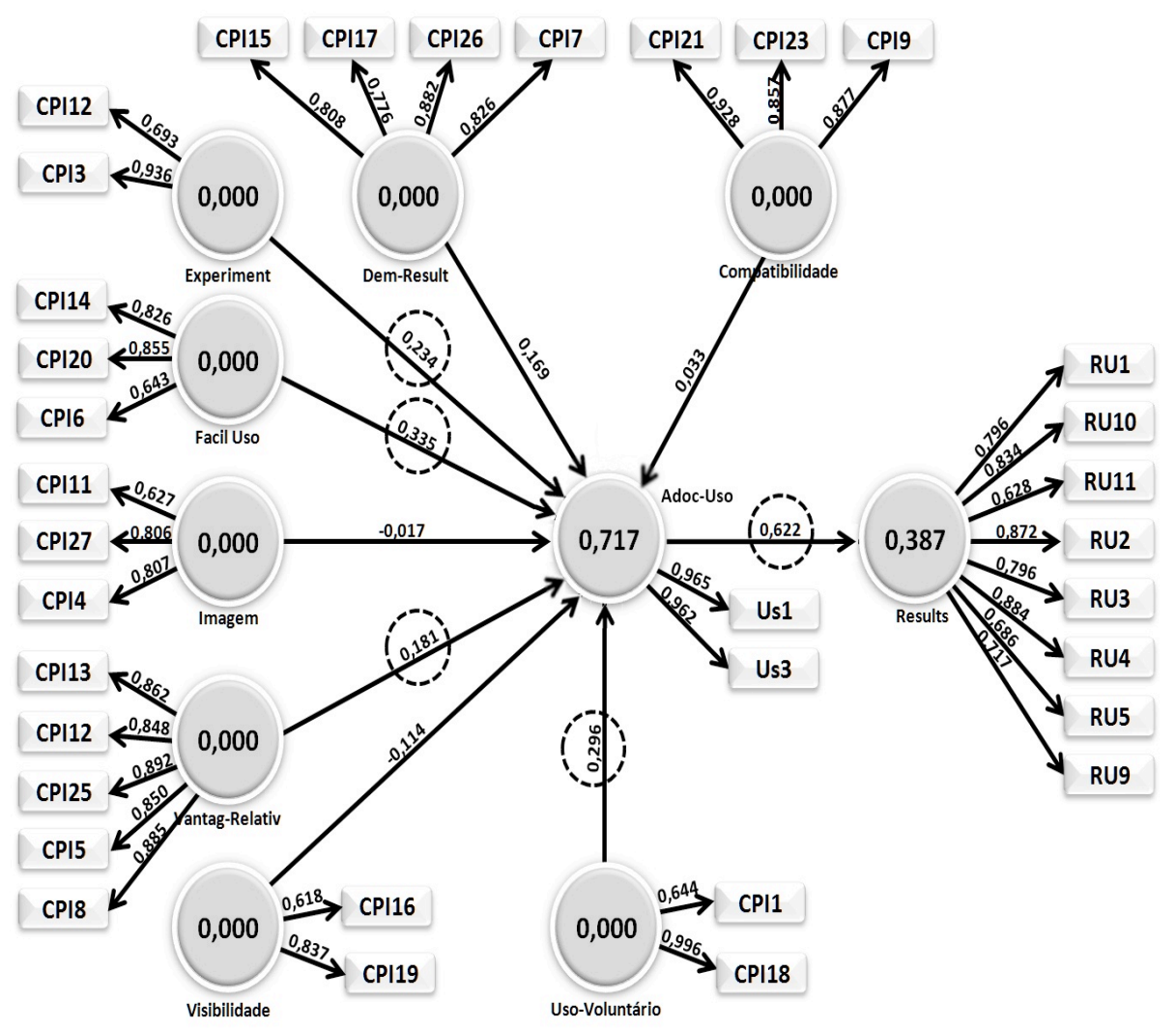

Fonte: Elaborado pelos autores.

Nas tabelas 1 e 2 apresentam-se os principais indicadores obtidos no processamento do modelo ajustado (sem as variáveis Us2, CPI10, CPI22, CPI24 e RU6). Na tabela 1 observa-se que os valores obtidos para o Alfa de Cronbach são superiores a 0,60, o que é recomendado pela literatura como valor de corte (HAIR Jr. et al., 2005). O mesmo aconteceu com a variância média explicada (VME) e com a com a confiabilidade composta, ambos com valores sempre acima de 0,50 conforme recomendado por Tenenhaus et al. (2004). 
Tabela 1: Indicadores da apuração do modelo ajustado

\begin{tabular}{l|c|c|c|c}
\hline \multicolumn{1}{c|}{ Variável } & $\begin{array}{c}\text { Alfa de } \\
\text { Cronbach }\end{array}$ & $\boldsymbol{V M E}$ & $\sqrt{\boldsymbol{V M E}}$ & $\begin{array}{c}\text { Confiabilidade } \\
\text { Composta }\end{array}$ \\
\hline Compatibilidade & 0,8654 & 0,7884 & 0,8879 & 0,9178 \\
\hline Demonstração de Resultado & 0,7597 & 0,6855 & 0,8280 & 0,8483 \\
\hline Experimentação & 0,6657 & 0,6783 & 0,8236 & 0,8049 \\
\hline Facilidade de Uso & 0,6960 & 0,6090 & 0,7804 & 0,8216 \\
\hline Imagem & 0,6276 & 0,6475 & 0,8047 & 0,7935 \\
\hline Uso Voluntário & 0,7287 & 0,7034 & 0,8387 & 0,8193 \\
\hline Vantagem Relativa & 0,9208 & 0,7528 & 0,8676 & 0,9383 \\
\hline Visibilidade & 0,6237 & 0,6542 & 0,8088 & 0,6982 \\
\hline Adoc-Uso & 0,9223 & 0,9279 & 0,9633 & 0,9626 \\
\hline Resultado do Uso & 0,9085 & 0,6099 & 0,7809 & 0,9251 \\
\hline
\end{tabular}

Fonte: Elaborada pelos autores.

Para melhor compreensão dos resultados obtidos pela modelagem de equações estruturais foram colocados na diagonal da tabela 2 os valores da raiz quadrada da variância média explicada da tabela 1.

Tabela 2: Correlações entre as variáveis no modelo ajustado

\begin{tabular}{|c|c|c|c|c|c|c|c|c|c|c|}
\hline & 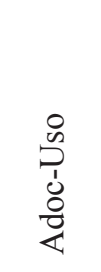 & 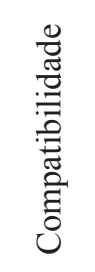 & 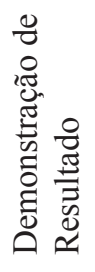 & 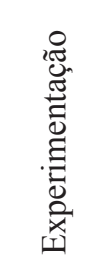 & 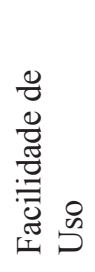 & 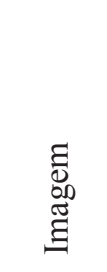 & 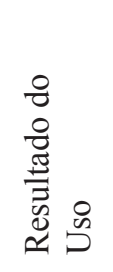 & 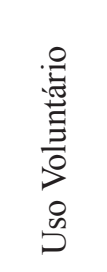 & 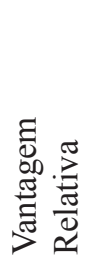 & 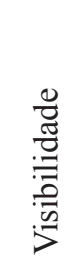 \\
\hline Adoc-Uso & 0,963 & & & & & & & & & \\
\hline Compatibilidade & 0,685 & $\mathbf{0 , 8 8 8}$ & & & & & & & & \\
\hline $\begin{array}{l}\text { Demonstração de } \\
\text { Resultado }\end{array}$ & 0,767 & 0,758 & 0,828 & & & & & & & \\
\hline Experimentação & 0,520 & 0,483 & 0,497 & $\mathbf{0 , 8 2 3}$ & & & & & & \\
\hline Facilidade de Uso & 0,735 & 0,770 & 0,809 & 0,473 & 0,780 & & & & & \\
\hline Imagem & 0,446 & 0,416 & 0,548 & 0,445 & 0,570 & 0,804 & & & & \\
\hline Resultado do Uso & 0,622 & 0,846 & 0,823 & 0,569 & 0,713 & 0,526 & 0,781 & & & \\
\hline Uso Voluntário & 0,367 & 0,166 & 0,302 & $-0,154$ & 0,126 & $-0,016$ & $-0,020$ & $\mathbf{0 , 8 3 9}$ & & \\
\hline Vantagem Relativa & 0,732 & 0,808 & 0,801 & 0,508 & 0,767 & 0,556 & 0,719 & 0,119 & $\mathbf{0 , 8 6 7}$ & \\
\hline Visibilidade & 0,318 & 0,454 & 0,534 & 0,088 & 0,570 & 0,302 & 0,430 & 0,121 & 0,466 & 0,809 \\
\hline
\end{tabular}

Fonte: Elaborada pelos autores.

Tenenhaus et al. (2004) recomendam que o valor da raiz quadrada da variância média deva ser maior que as correlações entre as variáveis em que eles se localizam (valores das linhas e colunas). Tal fato se confirmou como pode ser verificado nos valores destacados na diagonal da tabela 2. Este procedimento, denominado validade discriminante, visa testar se as variáveis latentes estudadas deveriam ser agrupadas ou não. Um agrupamento ocorreria caso fosse detectado um valor para a raiz quadrada menor que a correlação entre as variáveis. 


\subsection{Validação do Modelo Estrutural Proposto}

Na figura 2 podem ser localizados os coeficientes de regressão associados a cada uma das variáveis observadas (Vantagem Relativa, Uso Voluntário, Compatibilidade, Imagem, Facilidade de Uso, Demonstração de Resultado, Visibilidade e Experimentação) e quanto eles impactam na variável latente Adoc-Uso, bem como o quanto essa última afeta a variável latente Results (Resultado do Uso).

Os coeficientes de regressão padronizados indicam o quanto cada construto afeta as variáveis latentes, quando essas aumentam de uma unidade. A Facilidade de Uso apresenta o maior coeficiente de regressão $(0,335)$ com a variável Adoc-Uso, que é a maior contribuição para a variação de Adoc-Uso. Esta constatação está de acordo com Perez (2006) e Rogers (2003), que enfatizam que quanto maior a facilidade de uso percebida em uma inovação, maior será a sua taxa de adoção. Por sua vez, a variável Adoc-Uso apresenta um coeficiente de regressão igual a 0,622 com relação à variável Resultado do Uso.

Na figura 2 observa-se que os coeficientes de regressão padronizados das variáveis: Imagem, e Compatibilidade apresentam valores negativos ou muito pequenos $(-0,017$ e 0,033$)$. Consideraram-se esses valores como sendo próximos de zero, o que sugere pouca ou nenhuma contribuição à variação de Adoc-Uso. Uma explicação para o caso da Imagem é o fato de que os professores de Contabilidade que adotaram o Moodle, o fizeram, sem a pretensão de melhorarem sua imagem ou status social perante os demais professores do curso, ou de outros cursos.

Com relação à Compatibilidade deve-se ressaltar que boa parte dos professores que adotou o Moodle, não teve a oportunidade de acessar outro tipo de ferramenta que pudesse de alguma forma suprir suas necessidades. Outro aspecto a ser considerado é que o sistema ainda está sendo explorado, no que diz respeito às suas funções mais avançadas. As demais variáveis (Vantagem Relativa, Uso Voluntário, Facilidade de Uso, Experimentação, Visibilidade e Demonstração de Resultado) afetam significativamente a Adoção/Uso do Moodle.

Na figura 2 também podem ser observados os valores dos coeficientes de determinação da variância $\left(\mathrm{R}^{2}\right)$ das variáveis dependentes Adoc-Uso e Resultados do Uso. Esses coeficientes indicam o percentual de variância da variável dependente que é explicado pelas variáveis independentes. Os valores de $\mathrm{R}^{2}$ obtidos estão no interior dos círculos que representam essas variáveis. No caso da variável Adoc-Uso o valor do coeficiente de determinação da variância $\left(\mathrm{R}^{2}\right)$ obtido foi de $71,7 \%$. Esse resultado está de acordo com a proposição de Rogers (2003), para o qual as cinco características percebidas em uma inovação explicam de $49 \%$ a $85 \%$ da sua taxa de adoção. No caso da variável Resultado do Uso o valor do coeficiente de determinação da variância $\left(\mathrm{R}^{2}\right)$ obtido foi de $38,7 \%$.

Ainda na validação do modelo estrutural foi utilizado o algoritmo de bootstrapping (amostragem aleatória) do software SmartPLS com o parâmetro 300 para o número de casos e amostras. O objetivo foi realizar 300 simulações com o conjunto de dados para a obtenção dos resultados do teste da distribuição $t$ de Student. Os resultados do teste $t$ dependem do número de questionários respondidos. Para uma amostra de 31 respondentes (graus de liberdade) o valor da distribuição $t$ de Student é 2,04, para um intervalo de confiança de 95\% e significância 0,05. 
O teste $t$ de Student serve para testar a hipótese de que os coeficientes de correlação/ regressão sejam iguais a zero. Caso o resultado do teste $t$ seja igual ou superior a 2,04 a hipótese é rejeitada, ou seja, a correlação é significante. No processamento do algoritmo de bootstrapping observou-se que as variáveis latentes Imagem e Compatibilidade apresentaram, respectivamente, os valores 0,239 e 0,213 para o teste $t$, os quais são inferiores a 2,04, logo, elas foram excluídas do modelo inicial. Os valores obtidos no teste $t$ para as variáveis Demonstração de Resultado, Vantagem Relativa e Visibilidade $(1,977,1,904$ e 1,819) ficaram próximos do valor limite, por isso, optou-se por mantê-las no modelo. Um novo processamento sem as variáveis Imagem e Compatibilidade afetou muito pouco (segunda e terceira casa decimal) os novos coeficientes calculados.

As variáveis constantes do construto Imagem (CPI4, CPI11 e CPI27) dizem respeito a: perfil diferenciado, maior prestígio e status social do usuário de uma inovação tecnológica. Na universidade "Ômega", os professores do curso de Contabilidade não demonstraram ser afetados por essas variáveis pelo fato de usarem o sistema Moodle. Uma possível justificativa para a não aderência da variável Imagem pode ser devida ao fato de que alguns dos professores respondentes também lecionam em cursos como administração e economia. Isso está de acordo com os estudos de Raitoharju e Laine (2006) de que diferentes profissionais apresentam diferentes percepções sobre o uso de sistemas de informações. Outro fato a ser levado em consideração é que o Moodle é utilizado por um conjunto bem definido de professores e, nessa situação, os aspectos de "imagem" não se manifestam.

As demais variáveis (Demonstração de Resultado, Experimentação, Facilidade de Uso, Uso Voluntário, Vantagem Relativa e Visibilidade) validaram o modelo e afetaram diretamente o Uso, com destaque para a Vantagem Relativa. A Vantagem Relativa corresponde ao grau com o qual uma inovação é percebida como sendo melhor que o seu predecessor e também pode estar ligada a aspectos econômicos (ROGERS, 2003). Conforme indicado na tabela 3, as hipóteses H3 e H4 não foram aceitas (foram rejeitadas) e as demais hipóteses (H1, H2, H5, H6, H7 e H8) foram aceitas (não foram rejeitadas).

Tabela 3: Resultados finais do modelo proposto

\begin{tabular}{r|c|c|c|c}
\hline \multicolumn{1}{c|}{ Relação Estrutural } & $\begin{array}{c}\text { Coeficiente } \\
\text { Padronizado }\end{array}$ & $\begin{array}{c}\boldsymbol{t} \text {-value } \\
\mathbf{2} \mathbf{2 , 0 4}\end{array}$ & Hipótese & $\begin{array}{c}\text { Status da } \\
\text { Hipótese }\end{array}$ \\
\hline Vantagem Relativa ->Adoc-Uso & 0,181 & 1,904 & H1 & Aceita \\
\hline Uso Voluntário -> Adoc-Uso & 0,296 & 3,091 & H2 & Aceita \\
\hline Compatibilidade->Adoc-Uso & 0,033 & $\mathbf{0 , 2 1 3}$ & H3 & Não Aceita \\
\hline Imagem->Adoc-Uso & $-0,017$ & $\mathbf{0 , 2 3 9}$ & H4 & Não Aceita \\
\hline Facilidade de Uso->Adoc-Uso & $\mathbf{0 , 3 3 5}$ & 2,422 & H5 & Aceita \\
\hline Demonstração de Resultado->Adoc-Uso & 0,169 & 1,977 & H6 & Aceita \\
\hline Visibilidade->Adoc-Uso & $-0,114$ & 1,819 & H7 & Aceita \\
\hline Adoc-Uso->Resultado do Uso & 0,622 & 15,735 & H9 & Aceita \\
\hline
\end{tabular}

Fonte: Elaborada pelos autores. 


\section{CONCLUSÃO}

A abordagem quantitativa desta pesquisa permitiu verificar que as características percebidas em uma inovação são os fatores determinantes de sua adoção e uso. Estes resultados estão de acordo com as teorias desenvolvidas por Rogers (1983) e Moore e Benbasat (1991). O modelo originalmente proposto, derivado dos modelos estabelecidos pelos citados autores, mostrou-se ajustado de acordo com os parâmetros apresentados e conduziu a um melhor entendimento da adoção de inovações no âmbito da implantação de novos sistemas de informações. Ficou evidenciado que o uso de sistemas de informações acarreta, por parte de seus usuários, percepções que podem ter importantes reflexos nas tarefas e trabalho da organização.

No estudo realizado mereceram destaque as variáveis representadas pelas características percebidas: Facilidade de Uso, Experimentação, Vantagem Relativa e Uso Voluntário. Estas variáveis contribuíram positivamente na adoção do Moodle, com coeficientes notadamente superiores aos demais, explicando dessa forma boa parte do modelo proposto inicialmente. As características Imagem e Compatibilidade não foram consideradas como relevantes para adoção pelos usuários e isso se deve, possivelmente, ao fato de que, para estes usuários, o Moodle constitui uma ferramenta do dia-a-dia.

Também ficou evidenciado que as características percebidas explicam apenas uma parte da adoção de inovações. O grau de explicação obtido está de acordo com a teoria, mas também sugere a participação de outros fatores no processo de adoção, o que também é assinalado por Rogers (1983) e Larsen e McGuire (1998). Uma boa parte desses outros fatores pode eventualmente ser atribuída ao contexto social interno, por exemplo, a forma adotada para a comunicação da inovação, conforme sugere Rogers (2003). Finalmente, também ficou aparente que os resultados decorrentes da adoção da inovação e as melhorias obtidas pela sua introdução não se atém ao fenômeno da adoção.

$\mathrm{Na}$ instituição de ensino pesquisada, além de se conseguir oferecer melhores condições de ensino aos alunos, também se conseguiu melhorar serviços e processos já existentes. Pode-se então, argumentar que as variáveis do presente estudo têm reflexo imediato no uso do sistema e, dessa forma, os resultados são compatíveis aos obtidos por Yusof et al. (2008) que concluem que atitudes favoráveis, boa liderança, ambiente amigável e boa comunicação têm influência positiva no sucesso de adoção de sistemas, como é o caso do Moodle, adotado como ferramenta para apoio ao ensino em Contabilidade. Puderam-se observar alguns indícios de que uso do Moodle é mediador de seu sucesso.

Esta pesquisa teve como foco a inovação tecnológica definida pela ferramenta Moodle em uma única grande instituição de ensino da cidade de SP, portanto, os resultados ficam limitados ao âmbito desta instituição. Porém, os achados aqui relatados podem ser de alguma valia para outras instituições de ensino superior, para as quais o Moodle é pertinente. Deve-se destacar, que a instituição em questão é uma das precursoras do uso do Moodle em larga escala, tendo em vista a grande quantidade de usuários envolvidos. Assim, os resultados da pesquisa podem ser úteis na decisão, desenvolvimento e implantação de sistemas, bem como, na interpretação de resultados de projetos com esse escopo. O estudo relatado também sugere a possível ampliação do conceito de características percebidas, isto é, a incorporação de outros aspectos do contexto organizacional, como é o caso da comunicação e liderança, que possivelmente também afetam a adoção de inovações tecnológicas.

Por fim, sugere-se que esta pesquisa seja continuada utilizando-se amostras com um 
número maior de respondentes, com um número maior de instituições de ensino superior, inclusive, com instituições de outras regiões do Brasil. Outra possibilidade, na perspectiva de se poder contar com amostras maiores, seria a avaliação dos resultados do uso e da adoção pelos diferentes atores envolvidos, ou seja, aumentar a análise utilizando-se a percepção dos alunos.

\section{REFERÊNCIAS}

AHUJA, M. K.; THATCHER J. B. Moving beyond intentions and toward the theory of trying: effects of work environment and gender on post-adoption information technology use. MIS Quarterly, v. 29, n. 3, p. 427-459, 2005.

BYRNE, B. M. Structural equation modeling with AMOS - Basic concepts, applications, and programming. New Jersey: Lawrence Erlbaum Associates Publishers, 2001.

CAVALCANTE, M. T. L.; VASCONCELLOS, M. M. Base tecnológica para a educação na saúde: Objetos de aprendizagem e padrões. Anais do X Congresso Brasileiro de Informática em Saúde. Anais... Disponível em http://www.sbis.org.br/cbis/arquivos/789.pdf. Acessado em 01/12/2009, 2006.

COLE, J.; FOSTER, H. Using Moodle. 2 ed. USA: O`Reilly Media, 2008

DAHAWY, K.; KAMEL, S. The use of Information Technology in teaching accounting in Egypt: case of Becker Professional Review. Journal of Cases on Information Technology, v. 8, n. 3, p. 71-87, 2006.

DAVID, J. S.; MACCRACKEN, H.; RECKERS, P. M. J. Integrating technology and business process analysis into introductory accounting courses. Issues in Accounting Education, v. 18 n. 4, p. 417-427, 2003.

DRUCKER, P. F. Innovation and Entrepreneurship: practice and principles. Elsevier, 2004.

FAUL, F., ERDFELDER, E., BUCHNER, A., LANG, A. G. Statistical power analyses using G*Power 3.1: Tests for correlation and regression analyses. Behavior Research Methods, n. 41, p. 1149-1160, 2009.

GRAEML, A. R. Sistemas de Informação - O alinhamento da estratégia de TI com a estratégia corporativa. $2^{\text {a }}$. ed. São Paulo: Atlas, 2003.

HAIR Jr, J. F; ANDERSON, R. E.; TATHAM, R. L.; BLACK, W. C. Multivariate data analysis. 5.Ed. New Jersey: Prentice Hall. 1998

HAIR JR, J. F.; BABIN, B.; MONEY, A. H.; SAMOUEL, P. Fundamentos de métodos de pesquisa em administração. Porto Alegre: Bookman, 2005.

JELINEK, M. Organizational entrepreneurship in mature-industry firms: foresight, oversight, and invisibility. In: Technological Innovation. USA: Cambridge University Press, 1997.

KARAHANNA, E.; STRAUB, D. W.; CHERVANY, N. I. Information technology adoption 
across time: a cross-sectional comparison of pre-adoption and post-adoption beliefs. MIS Quarterly, v. 23, n. 2, p. 183-213, 1999.

KLINE, R. B. Principles and Practice of Structural Equation Modeling. 2. ed. New York: The Guilford Press, 2005.

LARSEN, T. J.; McGUIRE, E. Information Systems Innovation and Diffusion: issues and directions. Hershey: Idea Group Publishing, 1998.

LAUDON, Kenneth C.; LAUDON, Jane P. Sistemas de informação gerenciais. 9. ed. São Paulo: Pearson Prentice Hall, 2011.

LITTO, F. M. A inspiração e os adversários. In: ABRAEAD - Associação Brasileira de Ensino a Distância. Anuário Brasileiro de Educação Aberta e a Distância. São Paulo: Instituto Monitor, 2008.

MARCONI, M. A.; LAKATOS, E. M. Fundamentos de metodologia científica. 6. ed. São Paulo: Atlas, 2007.

MOORE, G. C.; BENBASAT, I. Development of an instrument to measure the perceptions of adopting an information technology innovation. Information Systems Research, v. 2, n. 3, p. 192-222, 1991.

O'BRIEN, J.A.; MARAKAS, G.M. Administração de Sistemas de Informação. Uma introdução. 13 ed. São Paulo: McGrawHill, 2008.

PÁDUA, E. M. M. Metodologia da pesquisa: abordagem teórico-prática. São Paulo: Papirus, 1996.

PENNINGS, J. M. Innovations as precursors of organizational performance. In: GALLIERS, R.; BAETS, W. J. (editores) Information Technology and Organizational Transformation: innovation for the $21^{\text {st }}$ century organization. USA: Wiley, 1998.

PEREZ, G. Adoção de inovações tecnológicas: Um estudo sobre o uso de sistemas de informação na área de saúde. Tese Doutorado USP/FEA. São Paulo, 2006.

RAITOHARJU, R.; LAINE, M. Exploring the differences in information technology acceptance between healthcare professionals. In: PROCEEDINGS OF THE 12 ${ }^{\text {th }}$ AMERICAN CONFERENCE ON INFORMATION SYSTEMS, Acapulco, México, p 2644-2651, August., 2006.

RODRIGUES, A. P.; AMARAL, V. F.; MORO, C. M.; BASTOS, L. C. Apoio à educação em medicina através da Internet. Anais do X Congresso Brasileiro de Informática em Saúde Disponível em http://www.sbis.org.br/cbis/arquivos/1055.pdf. Anais... Acessado em 01/12/2009, 2006.

ROGERS, E. M. Diffusion of innovation. 3 ed. New York: The Free Press, 1983.

ROGERS, E. M. Diffusion of innovation. 5 ed. New York: The Free Press, 2003. 
SCHUMPETER, J. A. A Teoria do Desenvolvimento Econômico. 3 ed. São Paulo: Abril Cultural, 1982.

TENENHAUS, M.; VINZI, V. E.; CHATELIN, Y. M.; LAURO, C. PLS Path Modeling. Computational Statistics \& Data Analysis, v. 48, p. 159-205, 2004.

TENG, J. T.; GROVER, V.; GÜTTLER, W. Information technology innovations: general diffusion patterns and its relationship to innovations characteristics. IEEE Transactions on Engineering Management, v. 49, n. 1, p.13-27, 2002.

TIDD, J.; BESSANT, J.; PAVITT, K. Managing Innovation: integrating technological, market and organizational change. 3 ed. USA: John Wiley \& Sons, 2005.

TURBAN, E.; LEIDNER, D.; MCLEAN, E.; WETHERBE, J. Information Technology for management - transforming organizations in the digital economy. New York: J. Wiley \& Sons, 2006.

TURBAN, E; LEIDNER, D.; McLEAN, E.; WETHERBE, J. Tecnologia da Informação para gestão. Transformando os negócios na economia digital. 6 ed. Porto Alegre: Bookman, 2010.

YUSOF, M. M.; KULGIS, J.; PAPAZAFEIROPOULOU, A.; STERGIOULAAS, L. K. An evaluation framework for Health Information Systems: human, organization and technologyfit factors. International Journal of Medical Informatics, v. 77, p. 386-398, 2008. 


\section{DADOS DOS AUTORES:}

\section{GILBERTO PEREZ}

Universidade Presbiteriana Mackenzie, Centro de Ciências Sociais e Aplicadas - CCSA.

R. da Consolação, 930 - Edifício Modesto Carvalhosa - Consolação

01302-907 - São Paulo, SP - Brasil

\section{SÉRGIO LEX}

Universidade Presbiteriana Mackenzie, Centro de Ciências Sociais e Aplicadas - CCSA.

R. da Consolação, 930 - Edifício Modesto Carvalhosa - Consolação

01302-907 - São Paulo, SP - Brasil

\section{ANA MARIA ROUX VALENTINI COELHO CESAR}

Universidade Presbiteriana Mackenzie, Centro de Ciências Sociais e Aplicadas - CCSA.

R. da Consolação, 930 - Edifício Modesto Carvalhosa - Consolação

01302-907 - São Paulo, SP - Brasil

\section{MOISÉS ARI ZILBER}

Universidade Presbiteriana Mackenzie, Decanato de Pesquisa e Pós-Graduação - DPPG. Av. Consolação, 930 Edifício João Calvino - $8^{\circ}$ andar - Consolação

01302-907 - São Paulo, SP - Brasil

\section{ALBERTO DE MEDEIROS JR.}

Universidade Presbiteriana Mackenzie, Centro de Ciências Sociais e Aplicadas - CCSA.

R. da Consolação, 930 - Edifício Modesto Carvalhosa - Consolação

01302-907 - São Paulo, SP - Brasil 